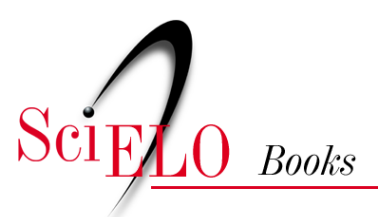

\title{
4 Tribo Nassauvieae Cass.
}

\author{
Marcelo Monge \\ Fátima Otavina Souza-Buturi \\ João Semir \\ Liliana Katinas
}

MONGE, M., SOUZA-BUTURI, F.O., SEMIR, J., and KATINAS, L. Tribo Nassauvieae Cass. In: ROQUE, N. TELES, A.M., and NAKAJIMA, J.N., comp. A família Asteraceae no Brasil: classificação e diversidade [online]. Salvador: EDUFBA, 2017, pp. 51-55. ISBN: 978-85-232-1999-4.

https://doi.org/10.7476/9788523219994.0006.

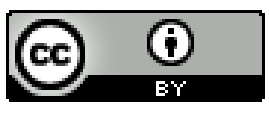

All the contents of this work, except where otherwise noted, is licensed under a Creative Commons Attribution 4.0 International license.

Todo o conteúdo deste trabalho, exceto quando houver ressalva, é publicado sob a licença Creative Commons Atribição $\underline{4.0}$. 


\title{
TRIBO NASSAUVIEAE CASS.
}

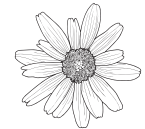 \\ Marcelo Monge \\ Fátima Otavina Souza-Buturi \\ João Semir \\ Liliana Katinas
}

Cassini (1819) propôs a primeira classificação para a família Asteraceae, na qual descreveu 20 tribos, dentre elas, Nassauvieae Cass. Segundo Cabrera (1977), a tribo já havia sido reconhecida anteriormente como um grupo taxonômico informal por Lagasca (1811), que agrupou todos os gêneros até então conhecidos de Asteraceae com corola bilabiada na "Ordo Chaenanthophorae", representada por 3 seções, das quais "Sectio I" era composta por 14 gêneros que, atualmente, pertencem a Nassauvieae. Posteriormente, Bentham (1873) reorganizou a família em 13 tribos, dentre elas, Mutisieae Cass., que foi subdividida em 5 subtribos, nas quais a tribo Nassauvieae foi englobada e transferida como subtribo, denominada Nassauviineae Less. O sistema de classificação de Bentham para a subtribo perdurou por mais de 100 anos (BAKER, 1876, 1884, CRISCI, 1974; CABRERA, 1977) e as primeiras modificações nessa classificação surgiram com os primeiros trabalhos de filogenia da família. Os recentes resultados de Funk e colaboradores $(2005,2009)$ e Panero e Funk $(2002,2008)$ evidenciaram o parafiletismo de Mutisieae, reconhecendo 3 clados relacionados à base da árvore filogenética: Onoserideae, Mutisieae e Nassauvieae. Embora esses resultados não alterem a circunscrição de Nassauviineae, a subtribo foi novamente elevada à categoria de tribo e é aceita como tal. Dessa forma, a tribo Nassauvieae, atualmente, é subordinada à subfamília Mutisioideae. 
Nassauvieae é composta por 25 gêneros e 315 espécies, apresentando distribuição neotropical (KATINAS et al., 2008), sendo um importante componente florístico nos Andes e Patagônia. (KATINAS et al., 2009; CABRERA, 1971) A maioria das espécies ocorre na América do Sul e algumas na América Central e América do Norte. A tribo é reconhecida pela presença dos capítulos discoides, flores com corola bilabiada e ramos do estilete truncados e penicelados. (BREMER, 1994; CABRERA, 1977; KATINAS et al., 2009)

\section{Descrição}

Ervas, subarbustos, arbustos e lianas. Folhas alternas ou rosuladas, simples, inteiras, pinatífidas ou pinatissectas, glabras ou com indumento, raramente com projeções espinescentes na margem e lâmina. Capitulescência racemiforme, corimbiforme, paniculiforme, raramente em glomérulo, ou capítulo solitário. Capítulos homógamos, discoides, raramente radiados ou disciformes, invólucro unisseriado ou multisseriado; receptáculo plano ou convexo, glabro ou com tricomas, paleáceo ou epaleáceo. Flores bissexuais, isomorfas, raramente dimorfas, corola bilabiada, lobo adaxial trilobado, lobos abaxiais solitários ou bilobados, revolutos (Figura 1M) ou eretos, raramente com corola tubulosa; anteras caudadas, apêndice apical obtuso ou agudo, cauda linear, glabro ou papiloso; estilete com ramos truncados, penicelados, raramente dorsalmente papilosos. Cipselas cilíndricas, obovoides, obcônicas, turbinadas, elipsoides, truncadas ou rostradas, com ou sem estrias, glabras ou com indumento; pápus unisseriado ou plurisseriado, cerdoso (Figura 1N), plumoso, paleáceo, ou raramente ausente.

No Brasil, Nassauvieae está representada por 7 gêneros e 37 espécies com distribuição extra-amazônica. (BFG, 2015) Cephalopappus Nees \& Mart. é um gênero monoespecífico e endêmico da floresta atlântica, ocorrendo no Nordeste e Sudeste; Criscia Katinas também é um gênero monoespecífico e ocorre no pampa, no estado do Rio Grande do Sul no Brasil, Argentina e Uruguai. (KATINAS, 1994) Holocheilus Cass. e Panphalea Lag. são gêneros sulamericanos restritos ao cone sul. Holocheilus está representado no Brasil por 6 espécies, dentre as quais 2 são endêmicas (Figura 3B). Panphalea possui 9 
espécies, e 3 delas são endêmicas do Brasil. Ambos os gêneros ocorrem em áreas úmidas da floresta atlântica e pampa; Jungia L.f. é um gênero americano e possui 2 espécies no Brasil, que ocorrem em áreas úmidas nas regiões centro-sul do país; Perezia Lag. (KATINAS, 2012) é um gênero sul-americano e, no Brasil, ocorrem 4 espécies e 2 subespécies, em áreas úmidas de campos de altitude da floresta atlântica (Figura 3C); Trixis P. Browne é um gênero neotropical que possui 15 espécies no Brasil, das quais 7 são endêmicas (KATINAS, 1996), sendo o gênero de Nassauvieae que apresenta a distribuição mais ampla no país (Figuras 3D-E).

\section{Chave de identificação para os gêneros de Nassauvieae no Brasil}

1. Pápus ausente 2

1'. Pápus presente 3

2. Lâmina foliar 4-11 cm larg., nunca pinatissecta; brácteas involucrais agudas; estigma arredondado, com tricomas nos ramos; cipsela suavemente rostrada no ápice

Cephalopappus

2'. Lâmina foliar 1-4 cm larg., as mais largas pinatissectas; brácteas involucrais apiculadas; estigma truncado, tricomas coletores no ápice; cipsela cilíndrica ou obovoide, truncada no ápice

Panphalea

3. Lâmina foliar palmada; receptáculo paleáceo; pápus plumoso Jungia 3’. Lâmina foliar não palmada; receptáculo epaleáceo; pápus cerdoso (Figura $1 \mathrm{~N})$

4. Receptáculo glabro Holocheilus

4’. Receptáculo piloso (Figura 1L). 5

5. Brácteas involucrais com ápice mucronado, margem hialina; corola lilás, rósea ou alva Perezia

5'. Brácteas involucrais com ápice agudo a arredondado, nunca mucronado, margem nunca hialina; corola amarela ou alaranjada 6 
6. Ervas escaposas; capítulos solitários ou aos pares Criscia

6'. Ervas caulescentes, subarbustos e arbustos; capitulescência com muitos capítulos Trixis

\section{Literatura Recomendada}

CABRERA, A. L. Asteraceae. In: CORREA, M. N. \& CABRERA, A. L. Flora Patagônica, Buenos Aires: INTA, 1971, v. 7. p. 1-151.

CASSINI, H. Suit du Sixième mémoire sur la famille des Synanthérées, contenant les caractères des tribus. Journal de Physique, de Chimie, d'Histoire Naturelle et des Arts, Paris, t. 88, p. 150-163, 1819.

BAKER, J. G. Compositae I. In: MARTIUS, C. P. von; EICHLER, A. W. (Ed.). Flora Brasiliensis. Lipsiae: [s.n.], 1876. v. 6, n. 2, p. 1-398.

BAKER, J. G. Compositae II - Mutisiaceae. In: MARTIUS, C. P. von; EICHLER, A. W. (Ed.). Flora Brasiliensis. Lipsiae: [s.n.], 1884, v. 6, n. 3, p. 339-398.

BRAZIL FLORA GROUP- BFG. Growing knowledge: an overview of seed plant diversity in Brazil. Rodriguésia, Rio de Janeiro, v. 66, n. 4, p. 10851113, 2015.

CABRERA, A. L. Mutisieae: systematic review. In: HEYWOOD, V. H.; HARBORNE, J. B.; TURNER, B. L. (Ed.). The Biology and Chemistry of the Compositae. London: Academic Press, 1977. v. 2. p. 1039-1066.

CRISCI, J. V. A numerical-taxonomic study of the subtribe Nassauviinae (Compositae, Mutisieae). Journal of the Arnold Arboretum, Cambridge, n. 55, p. 568-610, 1974.

BREMER, K. Asteraceae: cladistics and classification. Portland: Timber Press, 1994.

BENTHAM, G. Compositae. In: BENTHAM, G.; HOOKER, J. D. (Ed.). Genera Plantarum. London: Reeve, 1873, v. 2, n. 1, p. 163-533, 
FUNK, V. A. et al. Compositae metatrees: the next generation. In: FUNK, V. A. et al. (Ed.). Systematics, Evolution and Biogeography of Compositae. Vienna: IAPT, 2009. Chap. 44, p. 747-777.

FUNK, V. A. et al. Everywhere but Antarctica: using a supertree to understand the diversity and distribution of the Compositae. Biologiske Skrifter, Copenhagen, n. 55, p. 343-374, 2005.

KATINAS, L. et al. Mutisieae sensu stricto (Mutisioideae sensu strito). In: FUNK, V. A. et al. (Ed.). Systematics, Evolution, and Biogeography of Compositae. Vienna, Austria: International Association for Plant Taxonomy, 2009. p. 229-248.

KATINAS, L. Un nuevo género de Nassauviinae (Asteraceae, Mutisieae) y sus relaciones cladísticas con los géneros afines de la subtribu. Boletín de la Sociedad Argentina de Botánica, La Plata, n. 30, p. 59-70, 1994.

KATINAS, L. Revisión del género Perezia (Asteraceae). Boletín de la Sociedad Argentina de Botánica, La Plata, n. 47, p. 159-261, 2012.

KATINAS, L. Revisión de las especies sudamericanas del género Trixis (Asteraceae, Mutisieae). Darwiniana, Buenos Aires, n. 34, p. 27-108, 1996.

KATINAS, L. et al. The subfamily Mutisioideae (Asteraceae). The Botanical Review, Bronx, n. 74, p. 469-716, 2008.

LAGASCA, M. Dissertación sobre un orden nuevo de plantas de la classe de las compuestas. In: LAGASCA, M. Amenidades Naturales de les Españas. [S.1.: s.n.], 1811. n. 1, p. 26-44.

PANERO, J. L.; FUNK, V. A. Toward a phylogenetic subfamilial classification for the Compositae (Asteraceae). Proceedings of the Biological Society of Washington, Washington, v. 115, n. 4, p. 909-922, 2002.

PANERO, J. L.; FUNK, V. A. The value of sampling anomalous taxa in phylogenetic studies: major clades of the Compositae revealed. Molecular Phylogenetics and Evolution, Orlando, v. 47, n. 2, p. 757-782, 2008. 